\title{
TENDÊNCIAS OBSERVADAS EM INDICADORES DE EXTREMOS CLIMÁTICOS DE TEMPERATURA E PRECIPITAÇÃO NO ESTADO DO PARANÁ
}

\section{WANDERSON LUIZ SILVA, CLAUDINE DERECZYNSKI, MANYU CHANG, MARCOS FREITAS, BRUNO JUSTEN MACHADO, LEONARDO TRISTÃO, JANAINA RUGGERI}

\author{
Universidade Federal do Rio de Janeiro, Rio de Janeiro, RJ, Brasil
}

wanderson@ufrj.br, claudine@acd.ufrj.br, manyu@ivig.coppe.ufrj.br,mfreitas@ivig.coppe.ufrj.br, machadojusten@gmail.com, leotristaochargel@gmail.com, janaruggeri@gmail.com

Recebido Abril de 2013 - Aceito Agosto de 2014

\begin{abstract}
RESUMO
O presente trabalho faz uma análise das tendências de extremos climáticos baseada em indicadores calculados a partir de séries de dados observacionais diários de temperatura e de precipitação durante 35 anos em 20 estações meteorológicas do IAPAR, no Estado do Paraná. O objetivo é contribuir para estudos sobre avaliação de impactos e vulnerabilidade climática, requeridos para elaborar estratégias de adaptação às mudanças climáticas. Inicialmente as climatologias de temperatura do ar e de precipitação no Estado são revisitas. Com relação às tendências de extremos climáticos, os resultados dos indicadores associados à temperatura apontam para um padrão de aquecimento generalizado estatisticamente significativo em grande parte do Paraná. A porcentagem de dias e noites quentes no Estado aumentou consideravelmente a uma taxa de 0,1 a $0,4 \%$ /ano entre 1976 e 2010. As médias anuais das temperaturas mínimas e máximas indicam uma elevação em quase todo o Paraná em torno de $+0,02^{\circ} \mathrm{C} /$ ano no mesmo período. Os indicadores de temperatura mínima apresentam tendências de aumento mais significativas que os de temperatura máxima. Por outro lado, a maior parte dos indicadores de extremos climáticos associados à precipitação não apresenta significância estatística, com exceção de alguns poucos em distintas regiões do Estado. Destes, destacam-se apenas as tendências de elevação nos períodos secos ( $+0,25 \mathrm{~mm} / \mathrm{ano})$ em Pato Branco e Planalto no sudoeste do Paraná e de redução das chuvas fortes (-0,5 $\mathrm{mm} / \mathrm{ano}$ ) em Cambará, Ibiporã e Umuarama no norte do Estado.
\end{abstract}

Palavras-Chave: Climatologia; Mudanças Climáticas; Extremos Climáticos; Paraná.

\begin{abstract}
OBSERVED TRENDS IN CLIMATE EXTREME INDICATORS OF TEMPERATURE AND PRECIPITATION IN THE STATE OF PARANÁ

This paper analyzes the trends of climate extremes based on indicators calculated from daily observational temperature and precipitation data series during 35 years at 20 IAPAR meteorological stations,, in the State of Paraná. The objective is to contribute to assessing studies on climate impacts and vulnerability, required to develop adapting strategies to climate change. Initially, climatologic values of air temperature and precipitation in the State are revisited. With respect to trends in climate extremes, the results of the indicators associated with temperature indicate a widespread pattern of statistically significant warming in almost all Paraná State. The percentage of hot days and nights in the State increased significantly at a rate of 0.1 to $0.4 \%$ year between 1976 and 2010 . The annual minimum and maximum average temperatures indicate an increase in almost all Paraná of $+0.02^{\circ} \mathrm{C} /$ year over the same period. The minimum temperature indicators show more significant increasing trends than the maximum temperature does. Furthermore, most indicators of climate extremes associated with precipitation have no statistical significance, except for a few stations in different regions of the State. From these, only Pato Branco and Planalto, at southwestern Paraná show an elevation trend of the dry period $(+0.25 \mathrm{~mm} /$ year), and Cambará, Ibiporã and Umuarama, in northern State show a reduction $(-0.5 \mathrm{~mm} /$ year $)$ of heavy rainfall.
\end{abstract}

Keywords: Climatology; Climate Change; Climate Extremes; Paraná. 


\section{INTRODUÇÃO}

Durante décadas, a maior parte das análises de mudanças climáticas globais utilizando dados observacionais se baseava em mudanças nos valores médios de precipitação e de temperatura do ar (Alexander et al., 2006). Contudo, nem sempre um aumento da média está relacionado com um aumento nos extremos. As mudanças nos extremos como, por exemplo, redução dos dias frios, aumento da duração das ondas de calor, elevação na frequência de chuvas intensas ou de secas severas, causam expressivos impactos na sociedade e nos ecossistemas em geral (Karl et al., 1997; Easterling et al., 2000; Meehl et al., 2000 e Frich et al., 2002).

No Brasil, as inundações bruscas, as inundações graduais e os movimentos de massa são responsáveis pelo maior número de óbitos em termos de desastres naturais (CEPED, 2011). Tais desastres são deflagrados por chuvas intensas que atingem as regiões mais vulneráveis dos grandes centros urbanos, onde reside grande parte da população de renda mais baixa. Outro desastre natural de grande impacto no Brasil é a estiagem, em virtude da abrangência de grandes áreas atingidas, produzindo reflexos sobre as reservas hidrológicas locais e causando prejuízos à agricultura e à pecuária. Desta forma, um aumento na frequência de ocorrência de chuvas intensas e de secas severas poderia agravar o quadro de desastres naturais no Brasil.

Vincent et al. (2005) e Haylock et al. (2006) apresentam análises de indicadores de extremos climáticos na América do Sul relacionados, respectivamente, à temperatura do ar e à precipitação. Especificamente no Estado do Paraná estes autores utilizaram as estações Cambará $\left(23^{\circ} 00^{\prime} / 50^{\circ} 01^{\prime}\right)$, Curitiba $\left(25^{\circ} 25^{\prime} / 49^{\circ} 16^{\prime}\right)$ e Ponta Grossa $\left(25^{\circ} 22^{\prime} / 50^{\circ} 00^{\prime}\right)$ num período de aproximadamente 40 anos. Para a temperatura do ar, Vincent et al. (2005) mostram uma clara tendência de redução (aumento) na frequência de ocorrência das noites frias (quentes). Os resultados relacionados à precipitação, extraídos de Haylock et al. (2006), mostram condições mais úmidas em toda a Região Sul do Brasil, com totais pluviométricos anuais aumentando nas três estações localizadas no Paraná e com número de dias secos consecutivos em declínio nas estações Cambará e Ponta Grossa e em elevação na estação Curitiba.

A Região Sul do Brasil apresenta uma maior porcentagem de eventos extremos chuvosos em comparação com eventos extremos secos (Altamirano, 2010). Liebmann et al. (2004) e Obregón e Marengo (2007) mostram tendências significativas de aumento da precipitação total anual na segunda metade do século XX em praticamente toda a Região Sul do Brasil. No Estado do Paraná, os totais pluviométricos anuais foram analisados por Obregón e Marengo (2007) nas estações Castro $\left(24^{\circ} 46^{\prime} / 50^{\circ} 00^{\prime}\right)$, Morretes $\left(25^{\circ} 28^{\prime} / 48^{\circ} 49^{\prime}\right)$, Quedas do Iguaçu $\left(25^{\circ} 26^{\prime} / 52^{\circ} 53^{\prime}\right)$ e União da Vitória $\left(26^{\circ} 13^{\prime} / 51^{\circ} 04^{\prime}\right)$, todas pertencentes à Agência Nacional de Águas (ANA) indicando um aumento significativo em todas as estações, com exceção de Castro, onde se observou uma diminuição. Ainda no Paraná, os pesquisadores utilizaram dados diários de temperatura do ar das estações Curitiba $\left(25^{\circ} 25^{\prime} / 49^{\circ} 16^{\prime}\right)$ e Paranaguá $\left(25^{\circ} 31^{\prime} / 48^{\circ} 31^{\prime}\right)$ do Instituto Nacional de Meteorologia (INMET), mostrando elevação significativa da temperatura mínima anual média no período de 1961 a $2000 \mathrm{em}$ ambas as localidades.

Marengo et al. (2010) apresentam um aumento expressivo das noites quentes nos últimos anos, principalmente sobre o sudeste da América do Sul. Com relação à precipitação, foi observado um aumento de até 8 dias com precipitação acima de $10 \mathrm{~mm}$ no período analisado na Região Sul do Brasil. $\mathrm{O}$ indicador que representa o número máximo de dias secos consecutivos exibe tendências negativas na mesma região, com redução entre 10 e 40 dias, em concordância com Haylock et al. (2006).

Costa et al. (2009) analisaram séries históricas de dados diários de precipitação no período de 1977 a 2008 de 10 estações do Instituto Agronômico do Paraná (IAPAR) localizadas em diferentes regiões do Estado. Os autores identificaram nas séries de chuvas diárias a frequência de períodos consecutivos sem chuva com duração de 20 dias ou mais (CDD20) e também as ocorrências do maior período seco a cada ano (CDD). Os períodos secos mais longos ocorrem no norte, seguido do oeste, centro, sul e litoral do Paraná.

Diante de tais resultados, estudos de detecção de mudanças climáticas no Estado do Paraná são úteis no sentido orientar atividades em setores como a defesa e proteção civil, a agricultura, a saúde, o planejamento urbano, o gerenciamento de recursos hídricos, entre outros. Portanto, o objetivo deste trabalho é avaliar as tendências de indicadores de extremos climáticos relacionados à temperatura do ar e à precipitação nas últimas décadas no Estado do Paraná de um modo mais pormenorizado, a partir da utilização de dados diários de 20 estações do IAPAR no período de 1976 a 2010. Na Seção 2 são descritos os dados e a metodologia utilizados na pesquisa. Na Seção 3 apresenta-se uma revisão da climatologia da temperatura do ar e da precipitação sobre o Estado, gerada com dados climatológicos do INMET e do IAPAR, com o objetivo de suportar os resultados encontrados sobre as tendências de extremos climáticos. Na Seção 4 estão os resultados obtidos através dos indicadores de extremos climáticos e, finalmente, na Seção 5 são apresentadas as conclusões do trabalho.

\section{DADOS E METODOLOGIA}

Neste estudo, foram utilizadas séries de dados de totais pluviométricos diários e de temperaturas máxima e mínima diárias de 20 estações meteorológicas do IAPAR no decorrer 
do período de 1976 a 2010 (Tabela 1). Totais pluviométricos anuais e mensais médios, assim como médias mensais das temperaturas máxima e mínima do período de 1961-1990 de 17 estações pertencentes ao INMET (INMET, 2009) também foram utilizados para descrever a climatologia do Estado do Paraná (Tabela 2). Leva-se em consideração que os 35 anos de dados do IAPAR juntos aos 30 do INMET, ambos com período máximo de observação disponível, conseguem reproduzir de modo satisfatório as principais características de tais variáveis no Estado do Paraná. A distribuição espacial dos dois conjuntos de dados (IAPAR e INMET) e a topografia do Estado do Paraná são apresentadas na Figura 1. É importante ressaltar que as estações utilizadas nesta pesquisa não sofreram alterações posicionais ao longo do período analisado.

A partir dos dados observacionais do IAPAR, indicadores de extremos climáticos (Tabela 3 ) foram calculados utilizando-se o programa RClimDex (Zhang e Yang, 2004), desenvolvido pelo
Serviço Meteorológico Canadense. Tais indicadores de extremos climáticos são calculados, como definidos em Frich et al. (2002):

a) Índices baseados em percentis, incluindo a ocorrência anual de noites frias (TN10p), noites quentes (TN90p), dias frios (TX10p), dias quentes (TX90p), chuvas fortes (R95p) e chuvas intensas (R99p); os valores dos percentis foram calculados com base na climatologia de 1961-1990;

b) Índices absolutos que representam os valores máximo e mínimo anuais. Eles incluem a maior temperatura máxima anual (TXx), maior temperatura mínima anual (TNx), menor temperatura máxima anual (TXn), menor temperatura mínima anual (TNn), máxima precipitação anual em 1 dia (RX1day) e máxima precipitação anual em 5 dias consecutivos (RX5day);

c) Índices em que os limiares são definidos pelo número de dias em que a temperatura ou a precipitação ficaram abaixo ou acima de um valor fixo, incluindo a ocorrência anual de dias com temperatura máxima acima de $25^{\circ} \mathrm{C}(\mathrm{SU} 25)$, temperatura

Tabela 1 - Estações meteorológicas do IAPAR utilizadas na pesquisa. O código se refere ao número da estação cadastrado na Agência Nacional de Energia Elétrica (ANEEL).

\begin{tabular}{|l|c|c|c|c|c|c|}
\hline Código & Estação & $\begin{array}{c}\text { Latitude } \\
(\mathbf{S})\end{array}$ & $\begin{array}{c}\text { Longitude } \\
(\mathbf{W})\end{array}$ & $\begin{array}{c}\text { Altitude } \\
(\mathbf{m})\end{array}$ & Início & Fim \\
\hline $\mathbf{2 3 5 0 0 1 8}$ & Bandeirantes & $23^{\circ} 06^{\prime}$ & $50^{\circ} 21^{\prime}$ & 440 & 1977 & 2010 \\
\hline $\mathbf{2 2 5 1 0 2 7}$ & Bela Vista do Paraíso & $22^{\circ} 57^{\prime}$ & $51^{\circ} 12^{\prime}$ & 600 & 1976 & 2010 \\
\hline $\mathbf{2 3 5 0 0 1 7}$ & Cambará & $23^{\circ} 00^{\prime}$ & $50^{\circ} 02^{\prime}$ & 450 & 1976 & 2010 \\
\hline $\mathbf{2 6 5 2 0 0 3}$ & Clevelândia & $26^{\circ} 25^{\prime}$ & $52^{\circ} 21^{\prime}$ & 930 & 1976 & 2010 \\
\hline $\mathbf{2 5 5 0 0 2 5}$ & Fernandes Pinheiro & $25^{\circ} 27^{\prime}$ & $50^{\circ} 35^{\prime}$ & 893 & 1976 & 2010 \\
\hline $\mathbf{2 6 5 3 0 1 2}$ & Francisco Beltrão & $26^{\circ} 05^{\prime}$ & $53^{\circ} 04^{\prime}$ & 650 & 1976 & 2010 \\
\hline $\mathbf{2 5 5 1 0 1 0}$ & Guarapuava & $25^{\circ} 21^{\prime}$ & $51^{\circ} 30^{\prime}$ & 1058 & 1976 & 2009 \\
\hline $\mathbf{2 5 4 8 0 3 9}$ & Guaraqueçaba & $25^{\circ} 16^{\prime}$ & $48^{\circ} 32^{\prime}$ & 40 & 1980 & 2010 \\
\hline $\mathbf{2 3 5 1 0 1 1}$ & Ibiporã & $23^{\circ} 16^{\prime}$ & $51^{\circ} 01^{\prime}$ & 484 & 1976 & 2010 \\
\hline $\mathbf{2 3 4 9 0 3 0}$ & Joaquim Távora & $23^{\circ} 30^{\prime}$ & $49^{\circ} 57^{\prime}$ & 512 & 1976 & 2010 \\
\hline $\mathbf{2 5 4 9 0 9 1}$ & Lapa & $25^{\circ} 47^{\prime}$ & $49^{\circ} 46^{\prime}$ & 910 & 1989 & 2010 \\
\hline $\mathbf{2 5 5 2 0 0 9}$ & Laranjeiras do Sul & $25^{\circ} 25^{\prime}$ & $52^{\circ} 25^{\prime}$ & 880 & 1976 & 2007 \\
\hline $\mathbf{2 3 5 1 0 0 3}$ & Londrina & $23^{\circ} 22^{\prime}$ & $51^{\circ} 10^{\prime}$ & 585 & 1976 & 2010 \\
\hline $\mathbf{2 5 4 8 0 3 8}$ & Morretes & $25^{\circ} 30^{\prime}$ & $48^{\circ} 49^{\prime}$ & 59 & 1976 & 2010 \\
\hline $\mathbf{2 4 5 2 0 5 0}$ & Nova Cantu & $24^{\circ} 40^{\prime}$ & $52^{\circ} 34^{\prime}$ & 540 & 1977 & 2010 \\
\hline $\mathbf{2 4 5 3 0 0 3}$ & Palotina & $24^{\circ} 18^{\prime}$ & $53^{\circ} 55^{\prime}$ & 310 & 1976 & 2010 \\
\hline $\mathbf{2 3 5 2 0 1 7}$ & Paranavaí & $23^{\circ} 05^{\prime}$ & $52^{\circ} 26^{\prime}$ & 480 & 1976 & 2010 \\
\hline $\mathbf{2 6 5 2 0 3 5}$ & Pato Branco & $26^{\circ} 07^{\prime}$ & $52^{\circ} 41^{\prime}$ & 700 & 1979 & 2010 \\
\hline $\mathbf{2 5 5 3 0 1 5}$ & Planalto & $25^{\circ} 42^{\prime}$ & $53^{\circ} 47^{\prime}$ & 400 & 1976 & 2010 \\
\hline $\mathbf{2 4 5 0 0 1 1}$ & Telêmaco Borba & $24^{\circ} 20^{\prime}$ & $50^{\circ} 37^{\prime}$ & 768 & 1977 & 2010 \\
\hline $\mathbf{2 3 5 3 0 0 8}$ & Umuarama & $23^{\circ} 44^{\prime}$ & $53^{\circ} 17^{\prime}$ & 480 & 1976 & 2010 \\
\hline
\end{tabular}


Tabela 2 - Estações meteorológicas do INMET utilizadas no trabalho.

\begin{tabular}{|r|c|r|r|c|}
\hline Código & Estação & $\begin{array}{c}\text { Latitude } \\
(\mathbf{S})\end{array}$ & $\begin{array}{c}\text { Longitude } \\
(\mathbf{W})\end{array}$ & $\begin{array}{c}\text { Altitude } \\
(\mathbf{m})\end{array}$ \\
\hline 83783 & Campo Mourão & $24^{\circ} 03^{\prime}$ & $52^{\circ} 22^{\prime}$ & 616,4 \\
\hline 83813 & Castro & $24^{\circ} 47^{\prime}$ & $50^{\circ} 00^{\prime}$ & 1008,8 \\
\hline 83842 & Curitiba & $25^{\circ} 26^{\prime}$ & $49^{\circ} 16^{\prime}$ & 923,5 \\
\hline 83826 & Foz do Iguaçu & $25^{\circ} 33^{\prime}$ & $54^{\circ} 34^{\prime}$ & 154,0 \\
\hline 83775 & Guaíra & $24^{\circ} 05^{\prime}$ & $54^{\circ} 15^{\prime}$ & 230,1 \\
\hline 83834 & Guarapuava & $25^{\circ} 24^{\prime}$ & $51^{\circ} 28^{\prime}$ & 1135,8 \\
\hline 83836 & Irati & $25^{\circ} 28^{\prime}$ & $50^{\circ} 38^{\prime}$ & 837,0 \\
\hline 83811 & Ivaí & $25^{\circ} 00^{\prime}$ & $50^{\circ} 51^{\prime}$ & 808,0 \\
\hline 83769 & Jacarezinho & $23^{\circ} 09^{\prime}$ & $49^{\circ} 58^{\prime}$ & 470,7 \\
\hline 83766 & Londrina & $23^{\circ} 19^{\prime}$ & $51^{\circ} 08^{\prime}$ & 566,0 \\
\hline 83767 & Maringá & $23^{\circ} 24^{\prime}$ & $51^{\circ} 55^{\prime}$ & 542,0 \\
\hline 83860 & Palmas & $26^{\circ} 29^{\prime}$ & $51^{\circ} 59^{\prime}$ & 1090,5 \\
\hline 83844 & Paranaguá & $25^{\circ} 32^{\prime}$ & $48^{\circ} 31^{\prime}$ & 4,5 \\
\hline 83837 & Ponta Grossa & $25^{\circ} 06^{\prime}$ & $50^{\circ} 10^{\prime}$ & 868,5 \\
\hline 83867 & Rio Negro & $26^{\circ} 06^{\prime}$ & $49^{\circ} 48^{\prime}$ & 824,2 \\
\hline 83025 & São Mateus do Sul & $25^{\circ} 52^{\prime}$ & $50^{\circ} 23^{\prime}$ & 808,5 \\
\hline 83828 & Toledo & $24^{\circ} 24^{\prime}$ & $53^{\circ} 44^{\prime}$ & 574,2 \\
\hline
\end{tabular}

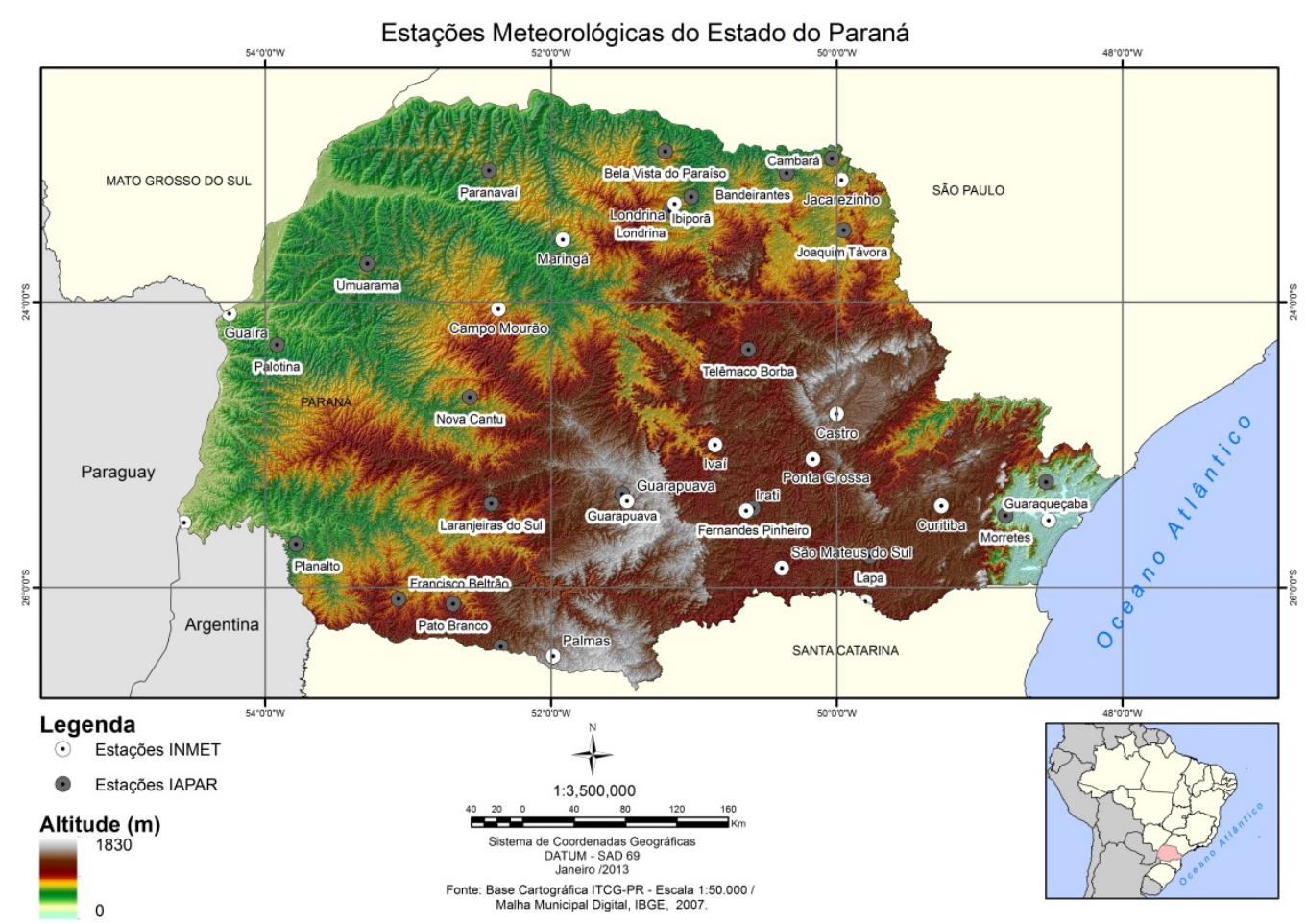

Figura 1 - Localização das estações meteorológicas do IAPAR e do INMET utilizadas no estudo, dispostas sobre o mapa de topografia da região pesquisada. 
mínima acima de $20^{\circ} \mathrm{C}$ (TR20) e número de dias no ano com precipitação acima de $30 \mathrm{~mm}$ (R30mm);

d) Índices com duração definida por períodos excessivos de calor, frio, chuva ou seca. Eles incluem a duração de ondas de calor (WSDI), ondas de frio (CSDI), períodos úmidos (CDW) e secos (CDD);

e) Outros índices incluem a precipitação anual total (PRCPTOT), distribuição média da precipitação anual total (SDII), temperaturas mínima (TMINmean) e máxima
(TMAXmean) anuais médias e a amplitude térmica anual média (DTR).

Os indicadores de extremos climáticos listados nos itens c e d envolvem, respectivamente, limiares e durações fixas. Contudo, é importante observar que nem sempre estes valores correspondem à realidade observada no Brasil. Por exemplo, SU25 significa "summer days", situação em que a temperatura máxima é superior a $25^{\circ} \mathrm{C}$, enquanto TR20 significa "tropical nights", quando a temperatura mínima é superior a

Tabela 3 - Definição e unidade dos indicadores de extremos climáticos analisados no trabalho. RR é o total pluviométrico diário. Dia úmido (seco) é definido por $\mathrm{RR}>=1 \mathrm{~mm}(\mathrm{RR}<1 \mathrm{~mm})$. TX e TN são temperaturas máxima e mínima diárias, respectivamente.

\begin{tabular}{|c|c|c|}
\hline Indicador & Definição & Unidade \\
\hline CDD & Número máximo de dias secos consecutivos no ano & dias \\
\hline CWD & Número máximo de dias úmidos consecutivos no ano & dias \\
\hline PRCPTOT & Precipitação anual total dos dias úmidos & $\mathrm{mm}$ \\
\hline R30mm & Número de dias no ano com $R R>=30 \mathrm{~mm}$ & dias \\
\hline R95p & Precipitação anual total dos dias em que RR > percentil 95 & $\mathrm{~mm}$ \\
\hline R99p & Precipitação anual total dos dias em que RR > percentil 99 & $\mathrm{~mm}$ \\
\hline RX1day & Máxima precipitação anual em 1 dia & $\mathrm{mm}$ \\
\hline RX5day & Máxima precipitação anual em 5 dias consecutivos & $\mathrm{mm}$ \\
\hline CSDI & Número máximo de dias consecutivos no ano com $\mathrm{TN}<$ percentil 10 & dias \\
\hline TMINmean & Temperatura mínima anual média & ${ }^{\circ} \mathrm{C}$ \\
\hline TN10p & Porcentagem anual de dias em que $\mathrm{TN}<$ percentil 10 & $\%$ \\
\hline TN90p & Porcentagem anual de dias em que $\mathrm{TN}>$ percentil 90 & $\%$ \\
\hline TNn & Menor temperatura mínima anual & ${ }^{\circ} \mathrm{C}$ \\
\hline TNx & Maior temperatura mínima anual & ${ }^{\circ} \mathrm{C}$ \\
\hline TR20 & Número de dias no ano em que $\mathrm{TN}>20^{\circ} \mathrm{C}$ & dias \\
\hline WSDI & Número máximo de dias consecutivos no ano com TX $>$ percentil 90 & dias \\
\hline TMAXmean & Temperatura máxima anual média & ${ }^{\circ} \mathrm{C}$ \\
\hline TX10p & Porcentagem anual de dias em que TX $<$ percentil 10 & $\%$ \\
\hline TX90p & Porcentagem anual de dias em que TX $>$ percentil 90 & $\%$ \\
\hline TXn & Menor temperatura máxima anual & ${ }^{\circ} \mathrm{C}$ \\
\hline TXx & Maior temperatura máxima anual & ${ }^{\circ} \mathrm{C}$ \\
\hline SU25 & Número de dias no ano em que $\mathrm{TX}>25^{\circ} \mathrm{C}$ & dias \\
\hline DTR & Amplitude anual média da temperatura diurna & ${ }^{\circ} \mathrm{C}$ \\
\hline
\end{tabular}


$20^{\circ} \mathrm{C}$. Para ondas de calor (WSDI) e de frio (CSDI), períodos úmidos (CDW) e secos (CDD), considera-se uma duração de, no mínimo, 6 (seis) dias consecutivos. Desta forma, caso tais limiares e durações fossem modificados os resultados seriam alterados. Entretanto, optou-se por manter os limiares e durações como definidos por Frich et al. (2002), para uma possível comparação futura com resultados em outras regiões do globo.

Os oito primeiros indicadores na Tabela 3 são relacionados à precipitação e os demais, à temperatura do ar.

Para a avaliação de tendências climáticas foi utilizado o teste estatístico não paramétrico de Mann-Kendall (Sneyers, 1975). Este teste considera que, na hipótese de estabilidade de uma série temporal, a sucessão de valores ocorre de forma independente e a distribuição de probabilidade deve permanecer sempre a mesma (série aleatória simples). O teste de MannKendall é o método mais apropriado para analisar a significância de possíveis mudanças climáticas em séries climatológicas (Goossens e Berger, 1986). Uma das vantagens deste teste é o fato do mesmo ser um teste não paramétrico, ou seja, os dados não precisam pertencer a uma distribuição particular. Outra vantagem é que seu resultado é menos afetado por valores outliers, pois seu cálculo é baseado no sinal das diferenças, e não diretamente nos valores da variável. O nível de confiança adotado foi de $95 \%$.

O método não-paramétrico (assumindo uma tendência linear) utilizado para estimar a magnitude de tendência, Curvatura de Sen (Sen, 1968), foi empregado em todas as séries. Para o cálculo da Curvatura de Sen, computam-se todas as curvaturas de todos os pares de valores usando uma série temporal. Como a Curvatura de Sen é insensível a valores outliers e dados ausentes, tal teste é mais rigoroso do que a usual curvatura de regressão e provê uma medida mais realística das tendências numa série temporal. Nos gráficos apresentados no item 4, as curvas de regressão (linhas de tendência lineares) são utilizadas apenas para efeito de visualização.

\section{O CLIMA NO ESTADO DO PARANÁ}

Nesta seção alguns aspectos da climatologia da temperatura do ar e da precipitação no Paraná são revisitados de maneira sucinta com o objetivo de apoiar o estudo de deteç̧ão da mudança climática no Estado.

A localização do Paraná, na transição entre os trópicos e as latitudes médias (aproximadamente entre 22 e $27^{\circ} \mathrm{S}$ ), seu relevo acidentado pela presença das Serras do Mar no sudeste, e da Serra Geral no sul, e a influência dos Oceanos Atlântico e Pacífico (remotamente), contribuem para acentuar as variabilidades espaciais e temporais nos regimes de precipitação e de temperatura do ar.

Nas Figuras 2 e 3 são apresentadas, respectivamente, as temperaturas máxima (TX) e mínima (TN) médias em janeiro e em julho. A distribuição espacial de TX e TN, com valores se elevando do sul/sudeste para o noroeste, sugere uma variabilidade latitudinal, devido ao aumento da radiação

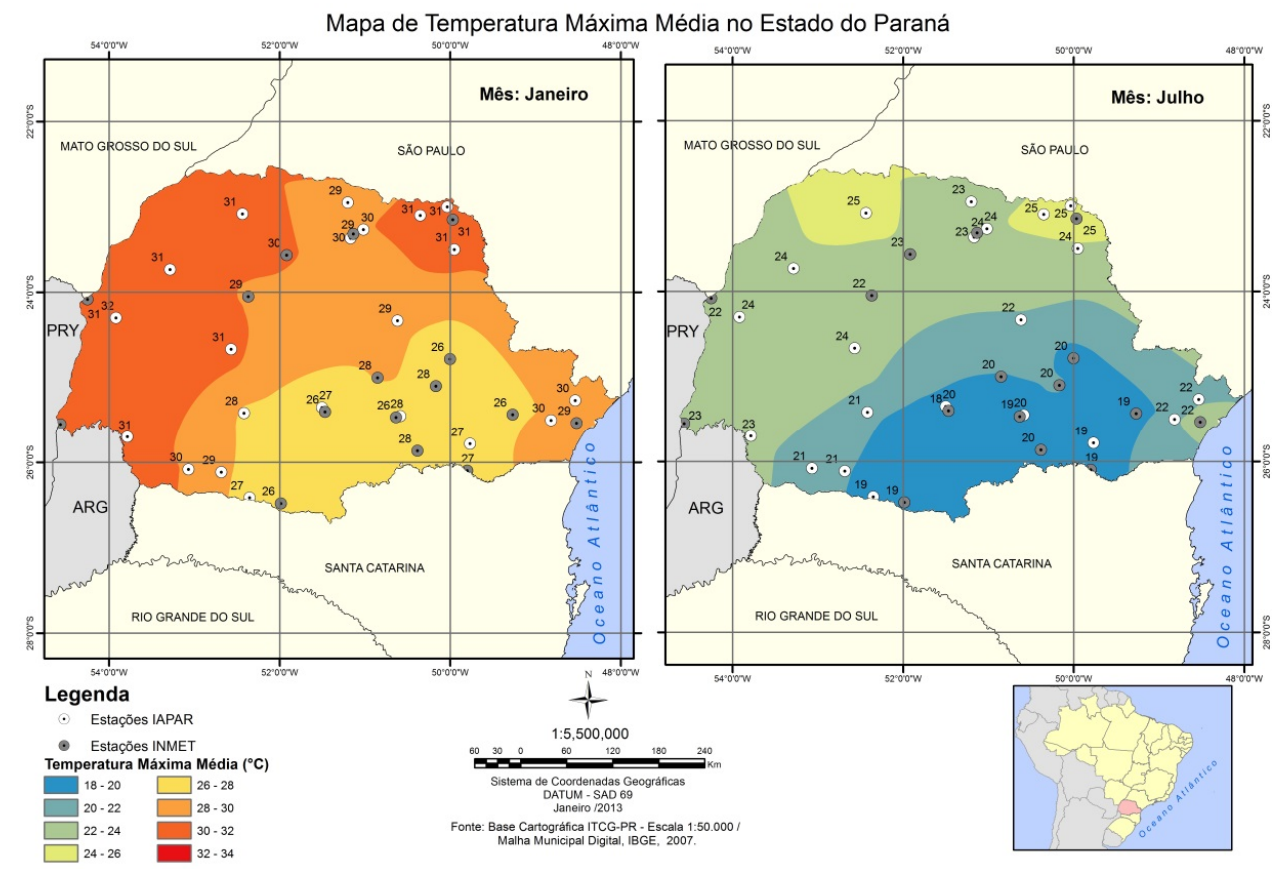

Figura 2 - Temperaturas máximas médias $\left({ }^{\circ} \mathrm{C}\right)$ obtidas a partir da climatologia das estações do IAPAR e do INMET para os meses de janeiro e de julho. 
solar em direção às menores latitudes e também à influência da topografia. Assim, menores valores de TX e TN são observados no sul/sudeste e sobre as regiões serranas do Paraná e os maiores valores no norte/noroeste e no litoral do Estado. Na estação meteorológica de Palmas do INMET localizada no extremo sul do Estado, a 1090,5 m de altitude, TX (TN) oscila entre $19,4^{\circ} \mathrm{C}$ $\left(4,7^{\circ} \mathrm{C}\right)$ em julho e $26,8^{\circ} \mathrm{C}\left(13,7^{\circ} \mathrm{C}\right)$ em janeiro. Por outro lado, na estação Paranavaí do IAPAR situada no noroeste do Estado, TX (TN) oscila entre $24,8^{\circ} \mathrm{C}\left(13,9^{\circ} \mathrm{C}\right)$ em julho e $31,1^{\circ} \mathrm{C}\left(21,1^{\circ} \mathrm{C}\right)$ em janeiro. Isto mostra o acentuado gradiente meridional de temperatura e a expressiva amplitude térmica anual na região. De acordo com Grimm (2009), no litoral a amplitude térmica anual é reduzida em função da influência da corrente marítima quente (corrente do Brasil), aumentando o conteúdo de umidade do ar, relacionado com a superfície mais aquecida do mar. Em Paranaguá, por exemplo, TX $(\mathrm{TN})$ varia entre $22,8^{\circ} \mathrm{C}\left(13,8^{\circ} \mathrm{C}\right)$ em julho e $29,9^{\circ} \mathrm{C}\left(21,3^{\circ} \mathrm{C}\right)$ em janeiro, exibindo uma amplitude térmica em torno de $7^{\circ} \mathrm{C}$.

Com relação à variabilidade interanual da temperatura do ar no Paraná, analisando-se as séries do IAPAR no período de 1976 a 2010, esta é mais acentuada para os meses de julho do que para os demais meses do ano. Em janeiro, por exemplo, TX (TN) apresenta um desvio-padrão de $1,1^{\circ} \mathrm{C}\left(0,8^{\circ} \mathrm{C}\right)$, enquanto que em julho, o valor do desvio-padrão chega a $1,7^{\circ} \mathrm{C}$ tanto para TX quanto para TN.

Barros et al. (2002) mostram que durante o inverno do ano em que um episódio El Niño - EN (La Niña - LN) começa (ano 0), há significativas anomalias positivas (negativas) de temperatura nos subtrópicos da América do Sul, com centro no norte da Argentina, mas estendendo-se sobre o sul do Brasil, incluindo o Estado do Paraná. De acordo com os autores, tais anomalias resultam da advecção quente (fria) de temperatura em baixos níveis proveniente do norte (sul). Na estação Palotina, localizada no oeste do Estado, as anomalias de TX média em julho foram de $+1,8^{\circ} \mathrm{C}$ em 1997 (ano de $\mathrm{EN}$ ) e de $-1,3^{\circ} \mathrm{C}$ em 2007 (ano de LN).

Os totais pluviométricos médios anual e nos meses de janeiro e julho são apresentados nas Figuras 4 e 5, respectivamente. A precipitação média anual (Figura 4) é mais elevada no litoral (chegando a $2434 \mathrm{~mm}$ em Guaraqueçaba) e no sudoeste (atingindo $2064 \mathrm{~mm}$ em Pato Branco), enquanto no nordeste e no sudeste predominam os menores indicadores pluviométricos do Estado (entre 1400 e $1500 \mathrm{~mm}$ ). De acordo com Grimm (2009), na costa leste da Região Sul, notadamente no Paraná, há significativa contribuição de efeito orográfico para a precipitação. Os ventos em superfície divergem da Alta Subtropical do Atlântico Sul, sopram perpendicularmente à costa, e são forçados a ascender pela presença da Serra do Mar, próxima ao litoral. Labraga et al. (2000) mostram que esta é uma região em que a convergência vertical de umidade é significativa, efeito que ajuda a produzir no leste do Paraná a maior precipitação de verão de toda a Região Sul. Ao longo do ano a precipitação é maior durante os meses de verão do que no inverno. Segundo Grimm et al. (1998) os maiores totais

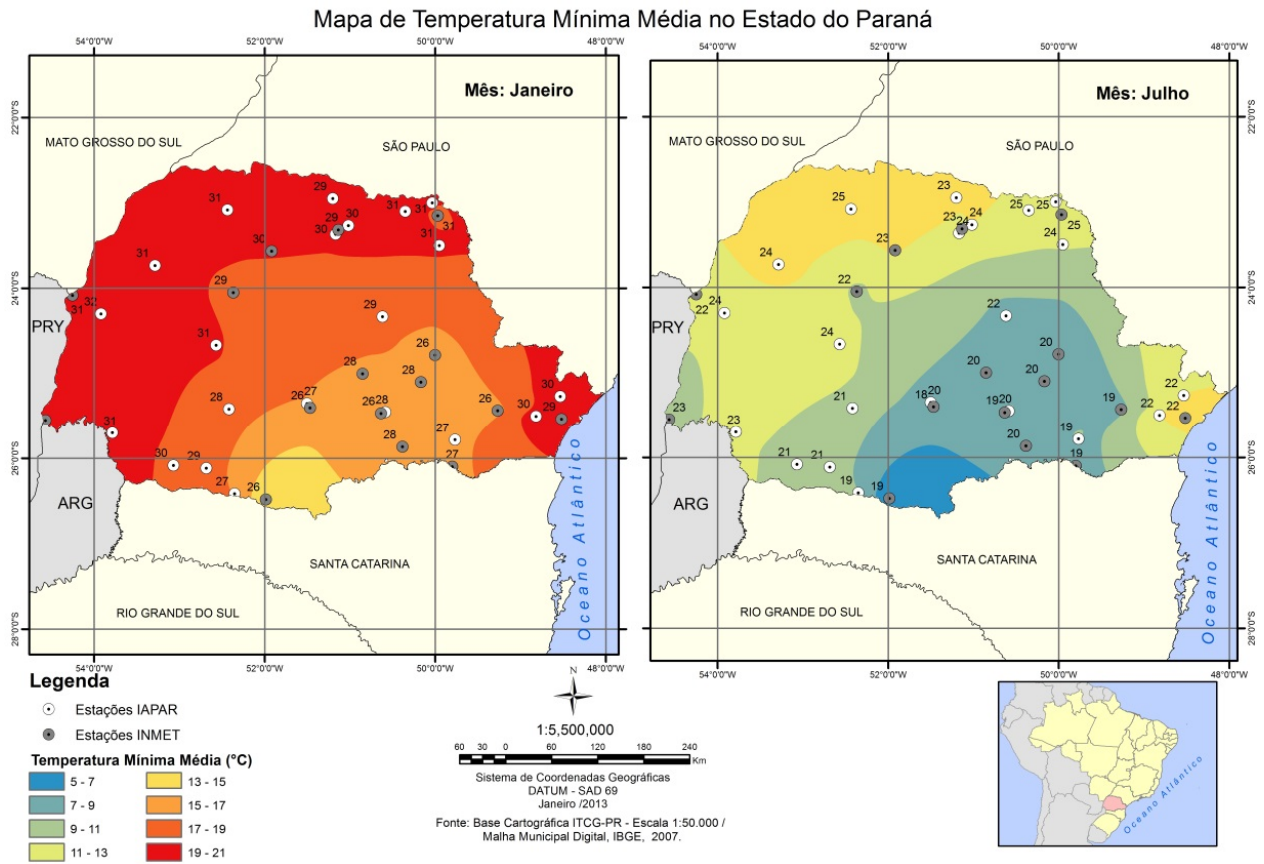

Figura 3 - Temperaturas mínimas médias $\left({ }^{\circ} \mathrm{C}\right)$ obtidas a partir da climatologia das estações do IAPAR e do INMET para os meses de janeiro e de julho. 
pluviométricos em todo o Paraná ocorrem de outubro a março, sendo o trimestre mais chuvoso de dezembro a fevereiro, exceto no oeste (litoral) do Estado onde o máximo pluviométrico ocorre entre outubro e dezembro (janeiro e março). De fato, a região central da América do Sul é caracterizada por um ciclo anual de precipitação bem definido, com seis meses secos (abril a setembro) e seis meses chuvosos (outubro a março), sendo este sistema de chuvas de verão denominado por alguns autores como "monção de verão" (Carvalho et al., 2002). Mechoso et al. (2005) constataram que o escoamento com padrão tipo Jato de Baixos Níveis (JBN) desempenha um papel importante no transporte de umidade da região amazônica até a parte central da

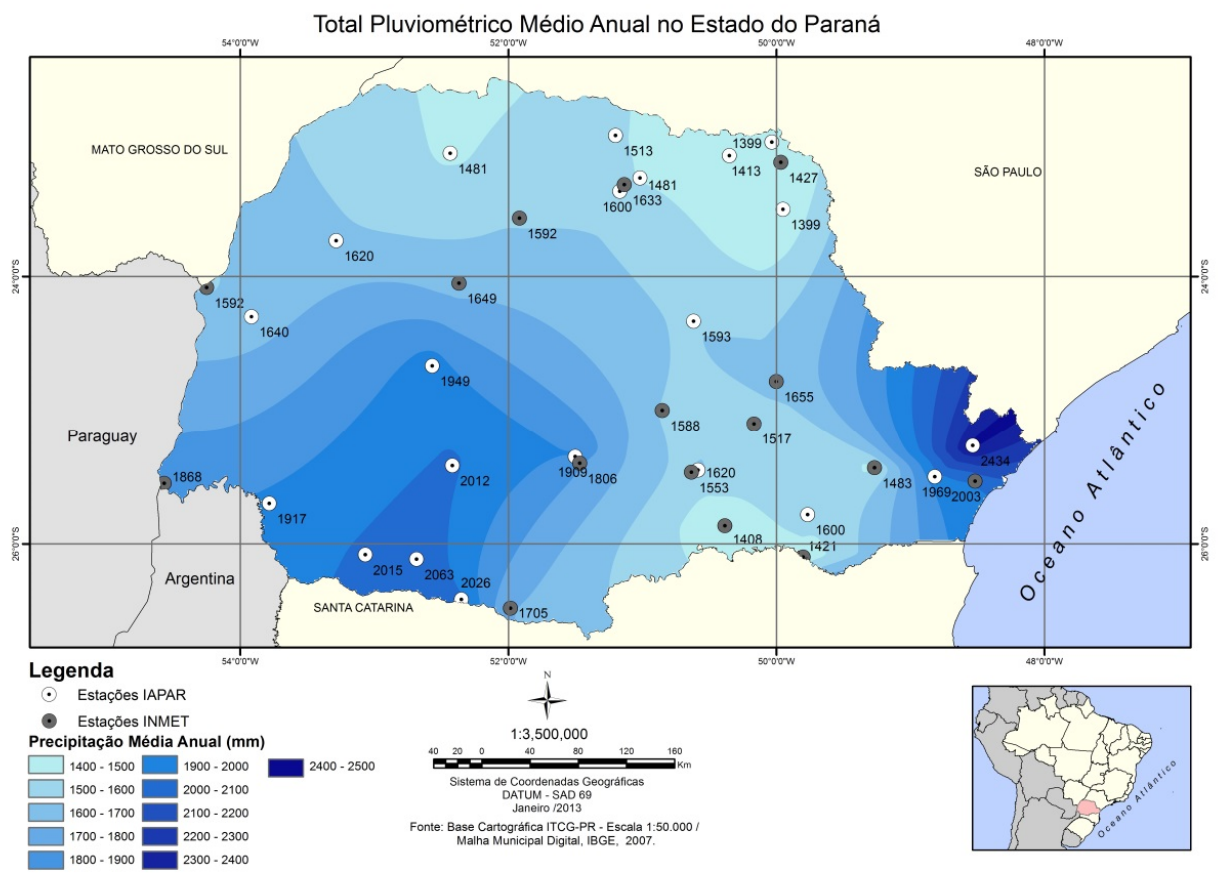

Figura 4 - Temperaturas mínimas médias $\left({ }^{\circ} \mathrm{C}\right)$ obtidas a partir da climatologia das estações do IAPAR e do INMET para os meses de janeiro e de julho

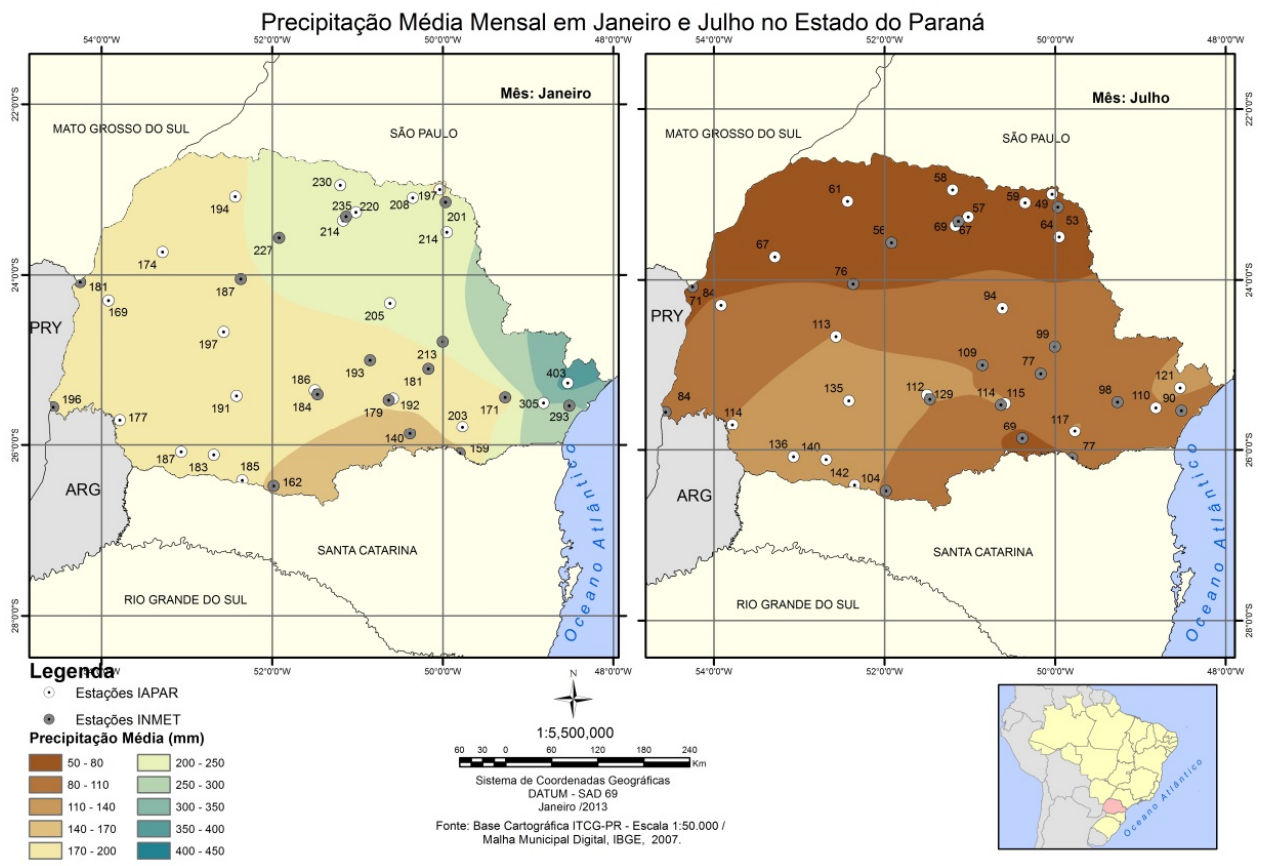

Figura 5 - Totais pluviométricos médios (mm) obtidos a partir da climatologia das estações do IAPAR e do INMET para os meses de janeiro e de julho. 
América do Sul, especialmente entre o Paraguai e o Estado do Paraná, aumentando assim a convergência do fluxo de umidade e a precipitação nesta região durante o período de monção.

Em janeiro e em julho (Figura 5) o máximo sobre o litoral se mantém, apesar da precipitação em janeiro (em torno de 400 $\mathrm{mm}$ ) ser aproximadamente quatro vezes maior do que em julho (cerca de $120 \mathrm{~mm}$ ) nesta área. De acordo com Grimm (2009), no verão o aquecimento da superfície e o aporte de umidade para o interior do continente instabilizam a atmosfera produzindo mais convecção. Tanto o aquecimento quanto a convergência de umidade são maiores no nordeste do Estado, nas proximidades da Zona de Convergência do Atlântico Sul (ZCAS). Os Sistemas Convectivos de Mesoescala (SCMs) também são frequentes e responsáveis por grande parte da precipitação total, principalmente nas estações de transição (outono e primavera). No inverno, a maior convergência de umidade desloca-se para o sul do Brasil em relação ao verão, localizando-se sobre o Estado do Rio Grande do Sul. As condições baroclínicas mais intensas ocorrem no inverno, devido ao maior gradiente latitudinal de temperatura na região (Grimm, 2009). Tal situação proporciona frequentes ciclogêneses e maior penetração de frentes que atingem o sul do Estado do Paraná. Desta forma, em julho nota-se que o máximo de precipitação ocorre no sudoeste do Estado, com valores de precipitação ligeiramente superiores aos encontrados no máximo do litoral.

Quanto à variabilidade interanual da precipitação no Paraná, vale destacar que o desvio-padrão dos totais pluviométricos médios anuais no Estado varia entre $227 \mathrm{~mm}$ no nordeste e $489 \mathrm{~mm}$ no sudoeste do Estado. O efeito de ENOS sobre a precipitação é mais forte do que sobre a temperatura do ar (Barros et al., 2002). De acordo com Grimm et al. (2000), na primavera, principalmente em novembro (ano 0) de EN (LN), fortes anomalias positivas (negativas) de precipitação ocorrem no Sul do Brasil. Estas anomalias estão associadas às piores enchentes na Bacia do Paraná-Prata. Na estação de Clevelândia (sudoeste do Paraná), por exemplo, foi verificada uma anomalia de $+485 \mathrm{~mm}$ em 1997 (ano 0 de EN) e de $-518 \mathrm{~mm}$ (ano 0 de LN). A frequência de eventos extremos de precipitação e os acumulados pluviométricos mensais também são enfaticamente influenciados pelas fases do ENOS nesta região (Grimm e Tedeschi, 2009). Além disso, existem correlações significativas entre a temperatura da superfície do mar (TSM) e os eventos extremos de precipitação na Região Sul do Brasil. De acordo com Cardoso (2005), para eventos muito secos, destacam-se anomalias positivas de TSM sobre a faixa subtropical do Oceano Atlântico.

A variabilidade climática na Região Sul do Brasil é ainda influenciada por diversos fenômenos atmosféricos em diferentes escalas espaciais e temporais que atuam sobre a América do Sul ao longo dos anos. Jones et al. (2004) investigaram relações entre a propagação para leste da Oscilação de Madden-Julian (OMJ) e ocorrências globais de precipitação extrema. Seus resultados indicam que a região leste da América do Sul, inclusive a Região Sul do Brasil, exibe fortes sinais de aumento na frequência de extremos de chuva durante situações ativas da OMJ.

A variabilidade da precipitação no Estado do Paraná é ainda afetada pelos bloqueios atmosféricos. Marques e Rao (1999) mostraram que, para os setores a leste e a oeste da América do Sul, a frequência de bloqueios é maior durante os meses de inverno e primavera, ocasionando longos períodos sem precipitação nestas áreas, inclusive no Sul do Brasil. De acordo com a distribuição espacial de dias secos consecutivos, verifica-se que no litoral e no sul do Estado, tais períodos secos duram em média 18 dias, enquanto que no norte paranaense a média é de 34 dias.

Cavalcanti e Ambrizzi (2009) descrevem a influência do padrão Pacífico-América do Sul na precipitação sobre a América do Sul. Os autores comentam que a presença de uma crista persistente, próximo ao sul da América do Sul, contribuiu para uma seca severa em várias áreas do Sul do Brasil em julho de 1989. Na fase oposta, um cavado nesta posição colaborou para a ocorrência de intensas enchentes na mesma região em julho de 1995.

\section{TENDÊNCIAS NOS INDICADORES DE EXTREMOS CLIMÁTICOS}

Os indicadores de extremos climáticos apresentados na Tabela 3 foram calculados através do programa RClimdex para as 20 estações do IAPAR no Estado do Paraná. Os resultados são apresentados a seguir, separadamente, para a temperatura do ar e a precipitação.

\subsection{Temperatura do ar}

A maior parte dos indicadores relacionados à temperatura do ar exibe tendências estatisticamente significativas em várias estações meteorológicas sobre o Estado do Paraná.

Os indicadores TN90p (noites quentes) e TX90p (dias quentes) que apresentam as porcentagens de dias no ano em que as temperaturas mínima e máxima, respectivamente, ficam acima do percentil 90, são mostrados na Figura 6. Em todo o Paraná, exceto no oeste, TN90p mostra elevação estatisticamente significativa, com maiores magnitudes na região central do Estado (Figura 6a). Em Guarapuava, o aumento de TN90p é de $0,31 \%$ de dias ao ano, passando de uma média de 15 noites quentes no final da década de 1970 para 50 noites quentes no final da década de 2000. Na Figura 6b, nota-se que o aumento de TX90p ocorre com maior intensidade no noroeste 
do Paraná, uma das regiões mais quentes do Estado, segundo a climatologia de temperatura apresentada anteriormente. Vale ressaltar a estação de Umuarama, que mostra uma taxa de elevação de $0,43 \%$ de dias ao ano. Nesta estação ocorria em média 29 dias quentes ao ano no final década de 1970, e ao final da década de 2000 este número passou para 76 dias.

Analisando-se as tendências de TN10p (noites frias) e TX10p (dias frios) verifica-se que ambos os indicadores encontram-se em declínio, sendo que para TN10p as taxas são estatisticamente significativas na maior parte do Paraná, exceto em algumas estações a leste e a oeste do Estado. Em Telêmaco Borba, por exemplo, a taxa é de $-0,21 \%$ de dias ao ano, onde observa-se em média 58 noites frias no final da década de 1970 e apenas 28 noites frias no final da década de 2000 .

As temperaturas mínima e máxima anuais médias (TMINmean e TMAXmean) indicam um aumento em quase todo o Estado em torno de $+0,02^{\circ} \mathrm{C} / \mathrm{ano}$, sendo que de forma mais significativa para a primeira. Logo, a amplitude anual média da temperatura diurna (DTR) mostra uma diminuição de $-0,02^{\circ} \mathrm{C} /$ ano, também estatisticamente significativa em algumas estações, principalmente no litoral. A exceção fica por conta de Umuarama, que aponta para um aumento estatisticamente significativo de DTR de $+0,02^{\circ} \mathrm{C}$, o que significa que a temperatura máxima aumenta a uma taxa superior à temperatura mínima.

Os indicadores WSDI e CSDI, que simbolizam respectivamente as ondas de calor e de frio, não apresentam tendências estatisticamente significativas no Estado, exceto WSDI em Umuarama, que mostra uma tendência estatisticamente significativa de aumento de 0,28 dia/ano. Nesta estação ocorria em torno de 5 dias quentes consecutivos ao ano no final da década de 1970, passando para uma média de 19 dias ao final da década de 2000.

Os indicadores absolutos TNn, TNx, TXn e TXx apresentam tendências de elevação em grande parte do Estado do Paraná, com algumas localidades mostrando tendências estatisticamente significativas. Para $\mathrm{TNx}$, as magnitudes das tendências ficam em torno de $+0,01^{\circ} \mathrm{C} / \mathrm{ano}$, enquanto que para TXx este valor é de $+0,03^{\circ} \mathrm{C} /$ ano. Assim como em outros estudos acerca dos indicadores de extremos climáticos no Brasil (Obregón e Marengo, 2007), tais tendências de aquecimento no Estado do Paraná podem ser atribuídas às mudanças no uso das terras locais, especialmente em termos de crescimento do perímetro urbano.

Os indicadores TR20 (número de dias no ano com temperatura mínima acima de $20^{\circ} \mathrm{C}$ ) e SU25 (número de dias no ano com temperatura máxima acima de $25^{\circ} \mathrm{C}$ ) também apontam para uma tendência de aumento em quase todo o território paranaense, sendo que o indicador TR20 apresenta os resultados mais significativos. A Figura 7 apresenta as tendências de TR20 para a estação Bandeirantes (norte do Paraná) e de SU25 para a estação Fernandes Pinheiro (sul do Estado), como exemplificação. O indicador TR20 está se elevando a uma taxa de $+1,13$ dia/ano na estação Bandeirantes. No final da década de 1970, Bandeirantes registrava em média

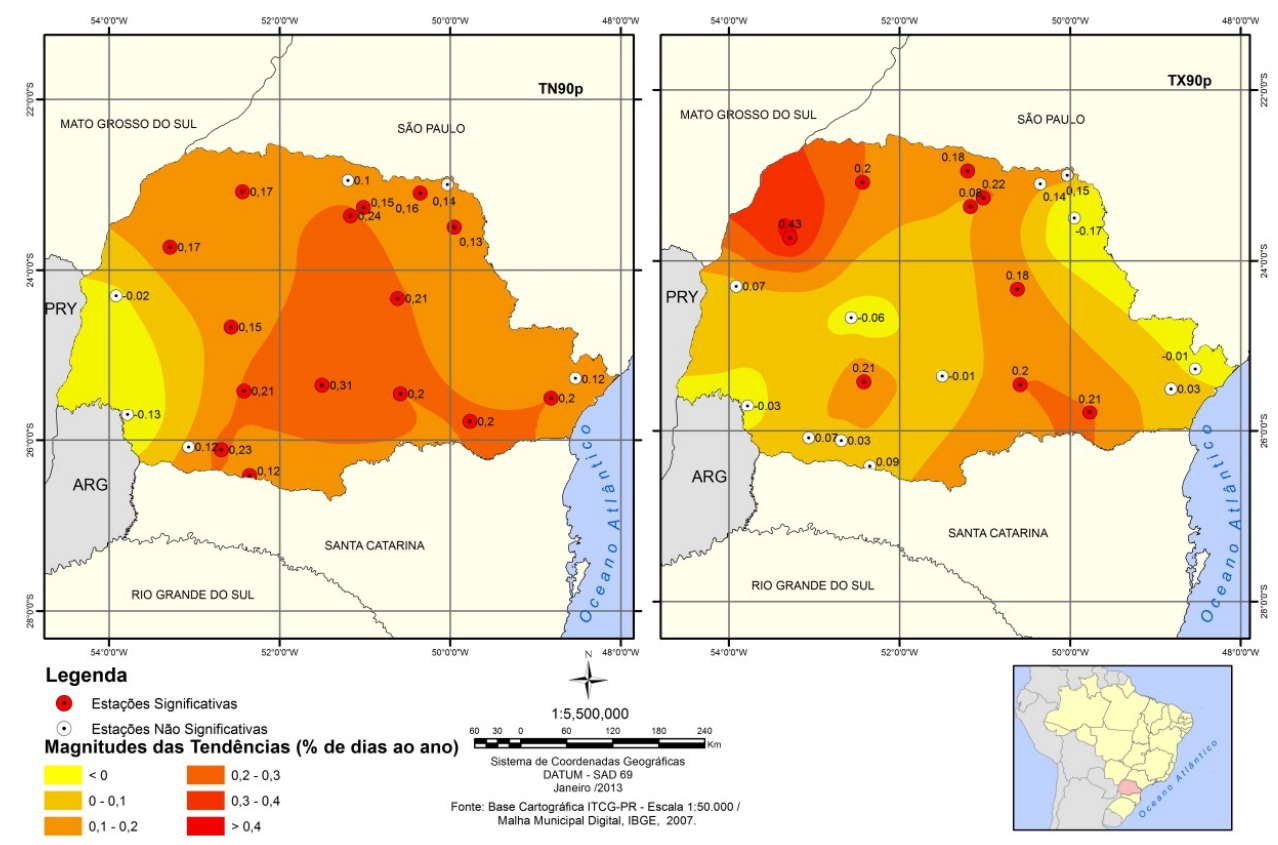

Figura 6 - Magnitudes das tendências dos indicadores de extremos climáticos de temperatura (a) TN90p (\%/ano) e (b) TX90p (\%/ano) no Estado do Paraná. 
59 noites com TR20, enquanto que ao final da década de 2000 este número já alcançava em torno de 90 dias. Já o indicador SU25 está aumentando a uma taxa de $+0,76$ dia/ano na estação Fernandes Pinheiro, onde se verifica uma média de 158 dias com SU25 no anos 1970 e cerca de 186 dias nos anos 2000.

\subsection{Precipitação}

Os indicadores associados à precipitação não apresentam tendências estatisticamente significativas na maior parte das estações analisadas no Estado do Paraná.

Para o indicador CDD, que apresenta o número máximo de dias secos consecutivos no ano, somente em Pato Branco e Planalto, ambas situadas no sudoeste do Paraná, existe tendência estatisticamente significativa (Figura 8), que é de aproximadamente $+0,25 \mathrm{dia} /$ ano. Nota-se que os valores de CDD variam entre 12 e 40 dias por ano. Em 1988 no período de 08 de julho a 16 de agosto em Pato Branco e de 10 de julho a 16 de agosto em Planalto as chuvas diárias não ultrapassaram $1 \mathrm{~mm}$, resultando em 40 (38) dias sem chuva na primeira (segunda) estação meteorológica. Em 1985 e 1991 observa-se que ocorreram, respectivamente, 30 e 36 dias consecutivos sem precipitação em Planalto, porém o mesmo não ocorreu em Pato Branco, com apenas 17 e 15 dias seguidos sem chuva nestes anos. A média nas duas estações para o período analisado é de
20,8 dias secos ao ano e, conforme mencionado no capítulo anterior, o sudoeste do Paraná possui um dos menores valores de CDD do Estado. Contudo, este valor está apresentando um sinal de tendência significativa de elevação.

A distribuição espacial do total pluviométrico anual dos dias úmidos (PRCPTOT) mostra uma leve diminuição no Estado (em 14 das 20 estações), especialmente na região norte e no centro. No litoral e em algumas áreas isoladas ao sudoeste do Paraná verifica-se ligeiro aumento. Contudo, é importante ressaltar que todas as tendências deste indicador não são estatisticamente significativas. Em Obregón e Marengo (2007) os autores encontraram também no litoral (estação Morretes) um aumento em PRCPTOT. Quanto ao indicador R30mm, que apresenta o número de dias no ano em que a precipitação acumulada diária ficou acima de $30 \mathrm{~mm}$, observa-se que mais da metade das estações não mostra tendência. Somente as estações Ibiporã e Morretes apontam para tendências significativas, porém contrárias, de $-0,14$ dia/ano e $+0,15$ dia/ ano, respectivamente.

Dos indicadores R95p e R99p, que somam os totais pluviométricos anuais dos dias em que a precipitação ficou acima dos percentis 95 e 99 estabelecidos pela climatologia, respectivamente, apenas o primeiro apresenta algum tipo de tendência estatisticamente significativa (redução na maior parte das estações). As chuvas intensas (R95p) apontam para

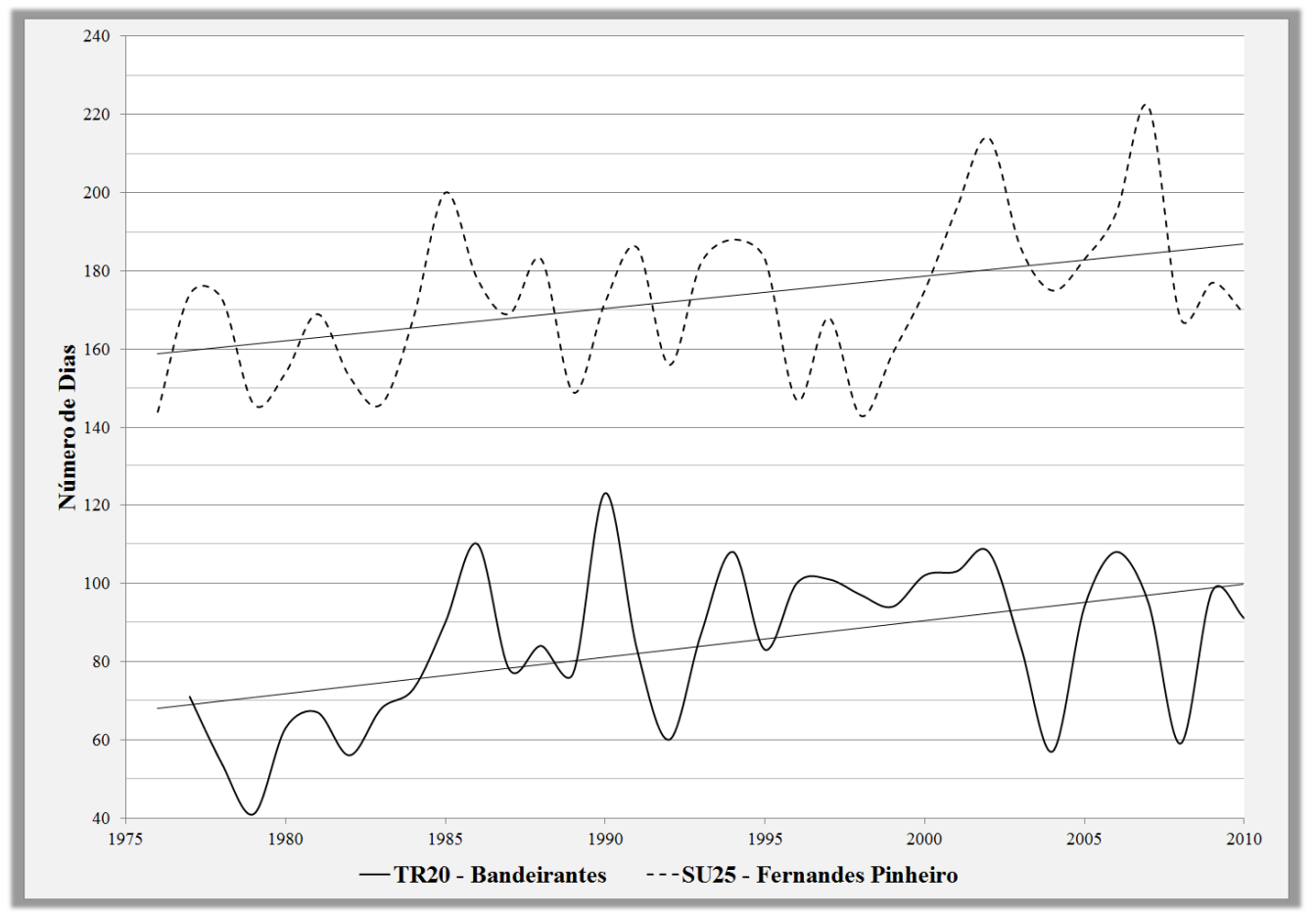

Figura 7 - Evolução temporal dos indicadores de extremos climáticos de temperatura TR20 (dia/ano) na estação Bandeirantes (linha cheia) e SU25 (dia/ano) na estação Fernandes Pinheiro (linha tracejada). 
uma diminuição estatisticamente significativa para as estações Cambará, Ibiporã e Umuarama (todas localizadas no norte do Paraná) de cerca de $-5 \mathrm{~mm} / \mathrm{ano}$. Os indicadores RX1day e RX5day, que apresentam o maior total pluviométrico anual em 1 dia e em 5 dias consecutivos, respectivamente, não mostram tendências significativas e suas magnitudes não obtiveram uma distribuição homogênea no Estado.

\section{CONCLUSÕES}

Neste trabalho elabora-se inicialmente uma revisão da climatologia da temperatura do ar e da precipitação no Estado do Paraná. A seguir é feita uma análise das tendências encontradas nos indicadores de extremos climáticos, definidos por Frich et al. (2002). Os dados observacionais utilizados são séries de aproximadamente 35 anos (1976-2010) de totais pluviométricos diários e de temperaturas máximas e mínimas diárias de 20 estações do IAPAR.

Os resultados do levantamento climatológico da região mostram que os menores valores de TX e TN são observados no sul/sudeste e sobre as regiões serranas do Paraná e os maiores valores no norte/noroeste e no litoral do Estado. Na estação meteorológica de Palmas do INMET localizada no extremo sul do Estado, a 1090,5 m de altitude, TX (TN) oscila entre $19,4^{\circ} \mathrm{C}\left(4,7^{\circ} \mathrm{C}\right)$ em julho e $26,8^{\circ} \mathrm{C}\left(13,7^{\circ} \mathrm{C}\right)$ em janeiro. Por outro lado, na estação Paranavaí do IAPAR situada no noroeste do
Estado, TX (TN) oscila entre $24,8^{\circ} \mathrm{C}\left(13,9^{\circ} \mathrm{C}\right)$ em julho e $31,1^{\circ} \mathrm{C}$ $\left(21,1^{\circ} \mathrm{C}\right)$ em janeiro. Com relação à precipitação, observa-se que os totais pluviométricos médios são mais elevados no litoral (chegando a $2434 \mathrm{~mm}$ em Guaraqueçaba) e no sudoeste (atingindo $2064 \mathrm{~mm}$ em Pato Branco), enquanto no nordeste e no sudeste predominam os menores indicadores do Estado (entre 1400 e $1500 \mathrm{~mm}$ ). O máximo de precipitação sobre o litoral se mantém ao longo do ano, apesar do valor em janeiro (em torno de $400 \mathrm{~mm}$ ) ser aproximadamente quatro vezes maior do que em julho (cerca de $120 \mathrm{~mm}$ ). Em julho, nota-se que o máximo de precipitação ocorre no sudoeste do Estado, com valores de precipitação ligeiramente superiores aos encontrados no máximo do litoral.

Os resultados dos extremos climáticos associados à temperatura apontam para um padrão de aquecimento generalizado estatisticamente significativo em grande parte do Estado do Paraná. A porcentagem significativa de dias e noites quentes (TX90p e TN90p) no Paraná está se elevando a uma taxa entre 0,1 e 0,4\%/ano. As temperaturas mínima e máxima anuais médias (TMINmean e TMAXmean) indicam um aumento em quase todo o Estado em torno de $+0,02^{\circ} \mathrm{C} /$ ano. Os indicadores relacionados à temperatura mínima exibem um sinal de tendência de elevação mais significativo do que os indicadores associados à temperatura máxima. Quanto aos indicadores absolutos, para TNx, as magnitudes das tendências ficam em torno de $+0,01^{\circ} \mathrm{C} / \mathrm{ano}$, enquanto que para TXx este valor é de

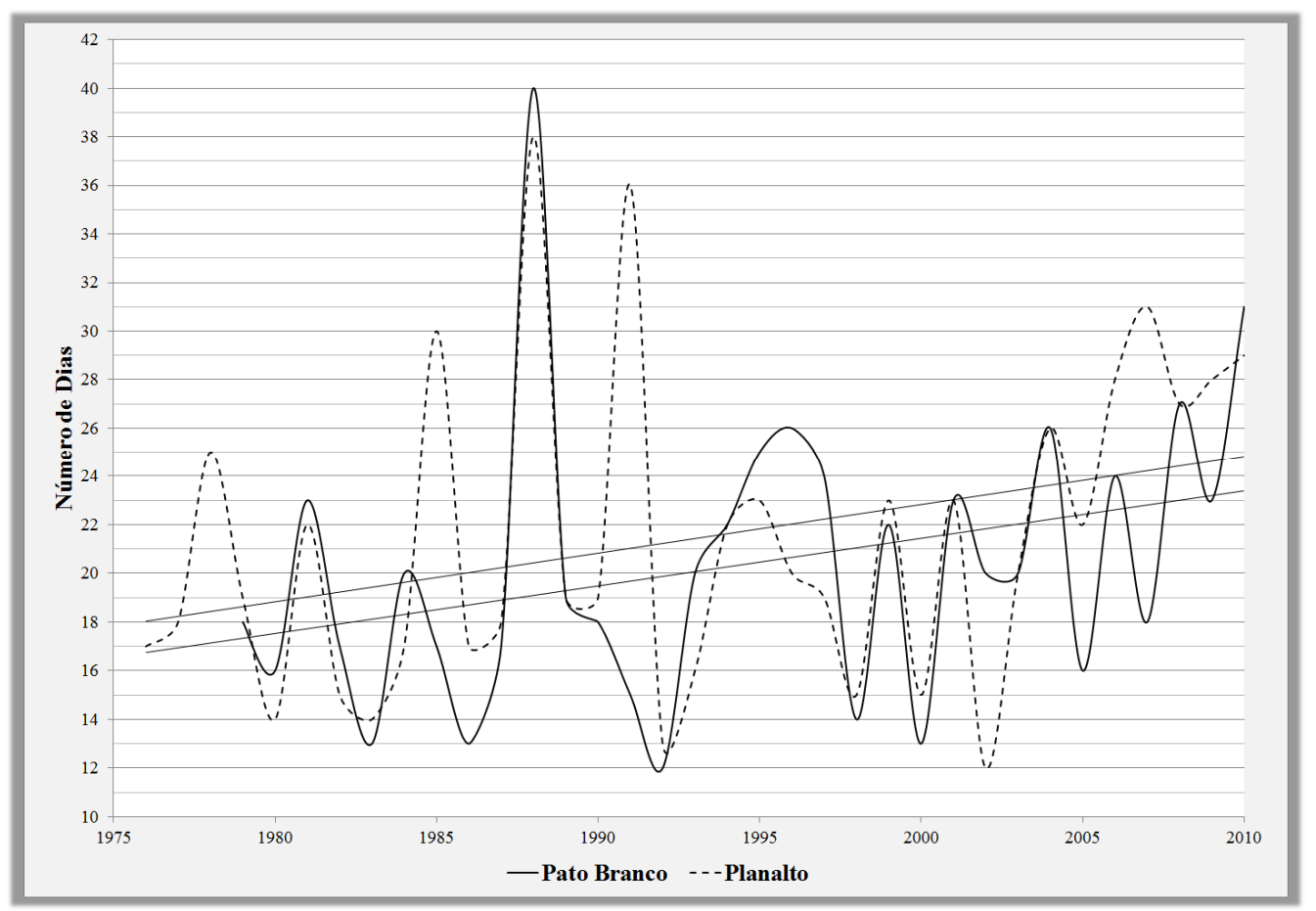

Figura 8 - Evolução temporal do indicador de extremo climático de precipitação CDD (dia/ano) nas estações Pato Branco (linha cheia) e Planalto (linha tracejada). 
$+0,03^{\circ} \mathrm{C} /$ ano. Tais resultados estão de acordo com as tendências de aquecimento encontradas por diversos pesquisadores para a América do Sul e para o Brasil (Vincent et al., 2005; Obregón e Marengo, 2007; Marengo et al., 2010).

A maior parte dos indicadores de extremos climáticos associados à precipitação mostrou-se sem significância estatística. Para o indicador CDD, somente em Pato Branco e Planalto existe tendência estatisticamente significativa, que é de aproximadamente $+0,25 \mathrm{dia} /$ ano. As estações Ibiporã e Morretes apontam para tendências significativas no indicador R30mm, mas contrárias, de -0,14 dia/ano e $+0,15$ dia/ano, respectivamente. As chuvas severas (R95p) mostram uma diminuição estatisticamente significativa para as estações Cambará, Ibiporã e Umuarama (norte do Paraná) de cerca de $-5 \mathrm{~mm} / \mathrm{ano}$.

\section{AGRADECIMENTOS}

Os autores agradecem ao Instituto Agronômico do Paraná (IAPAR) pelo fornecimento dos dados e ao Conselho Nacional de Desenvolvimento Científico e Tecnológico (CNPq) pelo suporte financeiro através da bolsa de Iniciação Científica concedida aos terceiro e quinto autores.

\section{REFERÊNCIAS BIBLIOGRÁFICAS}

ALEXANDER, L. V.; ZHANG, X.; PETERSON, T. C.; CAESAR, J.; GLEASON, B.; KLEIN TANK, A. M. G.; HAYLOCK, M.; COLLINS, D.; TREWIN, B.; RAHIMZADEH, F.; TAGIPOUR, A.; KUMAR, K. R.; REVADEKAR, J.; GRIFFITHS, G.; VINCENT, L.; STEPHENSON, D. B.; BURN, J.; AGUILAR, E.; BRUNET, M.; TAYLOR, M.; NEW, M.; ZHAI, P.; RUSTICUCCI, M.; VAZQUEZ-AGUIRRE, J. L. Global Observed Changes in Daily Climate Extremes of Temperature and Precipitation. Journal of Geophysical Research, v. 111, D05109, doi: 10.1029/2005JD006290, 2006.

ALTAMIRANO, R. J. A. Climatologia dos Eventos Chuvosos e Secos Severos, Extremos e muito Extremos usando o Índice de Precipitação Normalizada (SPI) para as Regiões CentroOeste, Sudeste e Sul do Brasil. Dissertação (Mestrado em Meteorologia) - Instituto Nacional de Pesquisas Espaciais (INPE), São José dos Campos, 2010.

BARROS, V.; GRIMM, A. M.; DOYLE, M. E. Relationship between Temperature and Circulation in Southeastern South America and its Influence from El Niño and La Niña Events. Journal of the Meteorological Society of Japan, v. 80, p. 21-32, 2002.

CARDOSO, A de O. Relações entre a TSM nos Oceanos Atlântico e Pacífico e as Condições Climáticas nas Regiões
Sul e Sudeste do Brasil. Tese (Doutorado em Meteorologia) - Instituto Astronômico e Geofísico (IAG/USP), São Paulo, 2005.

CARVALHO, L. M. V.; JONES, C.; LIEBMANN, B. Extreme Precipitation Events in Southeastern America and LargeScale Convective Patterns in the South Atlantic Convergence Zone, Journal of Climate, v.15, p. 2377-2394, 2002.

CAVALCANTI, I. F. A.; AMBRIZZI, T. Teleconexões e suas Influências no Brasil. In: Tempo e Clima no Brasil. Organizadores: Iracema Fonseca de Albuquerque Cavalcanti, Nelson Jesus Ferreira, Maria Gertrudes Alvarez Justi da Silva e Maria Assunção Faus da Silva Dias. São Paulo. Oficina de Textos, 2009.

CENTRO UNIVERSITÁRIO DE ESTUDOS E PESQUISAS SOBRE DESASTRES - CEPED. Atlas Brasileiro de Desastres Naturais 1991 a 2010: Volume Brasil. Universidade Federal de Santa Catarina, 2011. COSTA, A. B. F.; MORAIS, H.; CARAMORI, P. H.; RICE, W. S.; ATAÍDE, L. T.; YADA, I. F. U. Análise Climatológica de Dias Consecutivos sem Chuva no Estado do Paraná. Anais do III Simpósio Internacional de Climatologia. Canela (RS). Sociedade Brasileira de Meteorologia, 2009.

EASTERLING, D.; MEEHL, G.; PARMESAN, C.; CHANGNON, S.; KARL, T.; MEARNS, L. Climate Extremes: Observations, Modeling and Impacts. Science, v. 289, p. 2068-2074, 2000.

FRICH, P.; ALEXANDER, L. V.; DELLA-MARTA, P.; GLEASON, B.; HAYLOCK, M.; KLEIN TANK, A. M. G.; PETERSON, T. Observed Coherent Changes in Climatic Extremes during the Second Half of the Twentieth Century. Climate Research., v. 19, p. 193-212, 2002.

GOOSSENS, C.; BERGER, A. Annual and Seasonal Climatic Variations over the Northern Hemisphere and Europe during the Last Century. Annales Geophysicae, Berlin, v. 4, n. B4, p. 385-400, 1986.

GRIMM, A. M. Clima da Região Sul do Brasil. In: Tempo e Clima no Brasil. Organizadores: Iracema Fonseca de Albuquerque Cavalcanti, Nelson Jesus Ferreira, Maria Gertrudes Alvarez Justi da Silva e Maria Assunção Faus da Silva Dias. São Paulo. Oficina de Textos, 2009.

GRIMM, A. M.; BARROS, V. R.; DOYLE, M. E. Climate Variability in Southern South America associated with El Niño and La Niña events. Journal of Climate, v. 13, p. 35-38, 2000.

GRIMM, A. M.; FERRAZ, S. E. T.; GOMES, E. Precipitation Anomalies in Southern Brazil associated with El Niño and La Niña Events. Journal of Climate, v. 11, p. 2863-2880, 1998. GRIMM, A. M.; TEDESCHI, R. G. ENOS and Extreme Rainfall Events in South America. Journal of Climate, v. 22, p. 1589-1609, 2009. 
HAYLOCK, M. R.; PETERSON, T. C.; ALVES, L. M.; AMBRIZZI, T.; ANUNCIAÇÃO, Y. M. T.; BAEZ, J.; BARROS, V. R.; BERLATO, M. A.; BIDEGAIN, M.; CORONEL, G.; CORRADI, V.; GARCIA, V. J.; GRIMM, A. M.; KAROLY, D.; MARENGO, J. A.; MARINO, M. B.; MONCUNILL, D. F.; NECHET, D.; QUINTANA, J.; REBELLO, E.; RUSTICUCCI, M.; SANTOS, J. L.; TREBEJO, I.; VINCENT, L. A. Trends in Total and Extreme South American Rainfall in 1960-2000 and Links with Sea Surface Temperature. Journal of Climate, v. 19, p. 14901512, 2006.

INSTITUTO NACIONAL DE METEOROLOGIA INMET. Normais Climatológicas do Brasil 1961-1990. Organizadores: Andrea Malheiros Ramos, Luiz André Rodrigues dos Santos, Lauro Tadeu Guimarães Fortes. Brasília, DF. INMET, p. 465, 2009.

JONES, C.; CARVAlHO, L. M. V.; HIGGINS, R. W.; WALISER, D. E.; SCHEMM, J. K. E. Climatology of Tropical Intraseasonal Convective Anomalies: 1979-2002. Journal of Climate, v. 17, p. 523-539, 2004.

KARL, T.; NICHOLLS, N.; GREGORY, J. The Coming Climate. Scientific American, v. 276, p. 54-59, 1997.

LABRAGA, J. C.; FRUMENTO, O.; LÓPEZ, M. The Atmospheric Water Vapor Cycle in South America and the Tropospheric Circulation. Journal of Climate, v. 13, p. 1899-1915, 2000.

LIEBMANN, B.; VERA, C. S.; CARVALHO, L. M. V.; CAMELlONI, C. A.; HOERLING, M. P.; ALLURED, D.; BARROS, V. R.; BAEZ, J.; BIDEGAIN, M. An Observed Trend in Central South American Precipitation, Journal of Climate., v. 17, p. 4357-4367, doi:10.1175/3205.1, 2004.

MARENGO, J. A.; RUSTICUCCI, M.; PENALBA, O.; RENOM, M. An Intercomparison of Observed and Simulated Extreme Rainfall and Temperature Events during the Last Half of the Twentieth Century: part 2: Historical Trends. Climatic Change, v. 98, p. 509-529, doi: 10.1007/ s10584-009-9743-7, 2010.

MARQUES, R. F. C.; RAO, V. B. A Diagnosis of a Long-Lasting Blocking Event over the Southeast Pacific Ocean. Monthly Weather Review, v. 127, p. 1761-1776, 1999.
MEEHL, G.; KARL T.; EASTERLING, D.; CHANGNON, S.; PIELKE, R.; CHANGNON, D.; EVANS, J.; GROISMAN, P.; KNUTSON, T.; KUNKEL, K.; MEARNS, L.; PARMESAN, C.; PULWARTY, R.; ROOT, T.; SYLVES, R.; WHETTON, P.; ZWIERS, F. An Introduction to Trends in Extreme Weather and Climate Events: Observations, Socioeconomic Impacts, Terrestrial Ecological Impacts and Model Projections. Bulletin of the American Meteorological Society, v. 81, p. 413-416, 2000. MECHOSO, C. R.; ROBERTSON, A. W.; ROPELEWSKI, C. F.; GRIMM, A. M. The American Monsoon Systems: An Introduction. Genebra: World Meteorological Organization, WMO/TD, n. 1266 (TMRP Rep. n. 70), p. 197-206, 2005.

OBREGÓN, G.; MARENGO, J. A. Mudanças Climáticas Globais e seus Efeitos sobre a Biodiversidade: Caracterização do Clima no Século XX no Brasil: Tendências de Chuvas e Temperaturas Médias e Extremas. Relatório nº 2, Ministério do Meio Ambiente, 2007.

SEN, P. K. Estimates of the Regression Coefficient based on Kendall's Tau. Journal of American Statisites Association, v. 63, p. 1379-1389, 1968.

SNEYERS, R. Sur L'analyse Statistique des Series Dóbservations. Gênevè: Organisation Méteorologique Mondial, p. 192, 1975.

VINCENT, L. A.; PETERSON, T. C.; BARROS, V. R.; MARINO, M. B.; RUSTICUCCI, M.; CARRASCO, G.; RAMIREZ, E.; ALVES, L. M.; AMBRIZZI, T.; BERLATO, M. A.; GRIMM, A. M.; MARENGO, J. A.; MOLION, L.; MONCUNILL, D. F.; REBELLO, E.; ANUNCIAÇÃO, Y. M. T.; QUINTANA, J.; SANTOS, J. L.; BAEZ, J.; CORONEL, G.; GARCIA, J.; TREBEJO, I.; BIDEGAIN, M.; HAYLOCK, M. R.; KAROLY, D. Observed Trends in Indices of Daily Temperature Extremes in South America 1960-2000. Bulletin of the American Meteorological Society, v. 18, p. 5011-5023, 2005.

ZHANG, X.; YANG, F. RClimDex (1.0) - User Manual. Climate Research Branch Environment Canada Downsview, Ontario, Canada, 2004. 